\title{
O EXCESSO E A FALTA \\ EM EU SOU SARTORI \\ E O MEU PARTIDO \\ É O RIO GRANDE
}

EL EXCESO Y LA FALTA EN EU SOU SARTORI E O MEU PARTIDO É O RIO GRANDE

THE EXCESS AND THE LACK IN EU SOU SARTORI E O MEU PARTIDO É O RIO GRANDE

Ercília Ana Cazarin*

Universidade Católica de Pelotas

\author{
Maria Inês Gonçalves Medeiros Cordeiro** \\ Universidade Católica de Pelotas | Instituto Federal Sul-Rio-Grandense
}

\begin{abstract}
RESUMO: Este trabalho, ancorado na teoria da Análise de Discurso com filiação em Michel Pêcheux, tem como objetivo central analisar o enunciado EU SOU SARTORI E O MEU PARTIDO É O RIO GRANDE, proferido pelo então candidato ao governo do Estado do Rio Grande do Sul, José Ivo Sartori, durante a campanha eleitoral de 2014. Pretendemos, a partir desta investigação, proporcionar reflexões em torno de questões que possam, na verticalidade do discurso, auxiliar na compreensão do funcionamento discursivo do excesso e da falta, presentes em nosso objeto de discurso, concebidos como possíveis limites e interdições impostos ao sujeito. O excesso permite a instauração do efeito de verdade, enquanto a falta configura-se como uma das políticas do esquecimento. Ambos os funcionamentos instauram efeitos de sentido que podem deslocar, transformar, manter e/ou apagar sentidos.
\end{abstract}

PALAVRAS-CHAVE: Discurso Político. Excesso. Falta. Efeito de verdade. Políticas do Esquecimento.

RESUMEN: Este trabajo está ancorado en la teoría del análisis del discurso con filiación en Michel Pêcheux y tiene como objetivo central analizar el enunciado EU SOU SARTORI E O MEU PARTIDO É O RIO GRANDE, proferido por el candidato al gobierno del Estado del Rio Grande del Sur, José Ivo Sartori, durante la campaña electoral de 2014. Pretendemos, a partir de esta investigación, proporcionar reflexiones en torno a cuestiones que puedan, en la verticalidad del discurso, auxiliar en la comprensión del funcionamiento discursivo del exceso y de la falta, presentes en nuestro objeto de discurso, concebidos como posibles límites e interdicciones impuestos al sujeto. El exceso permite la instauración del efecto de verdad, mientras la falta se configura como una de las políticas del olvido. Ambos funcionamientos instauran efectos del sentido que pueden dislocar, transformar, mantener y/o borrar sentidos.

PALABRAS-CLAVE: Discurso Político. Exceso. Falta. Efecto de Verdad. Políticas del Olvido.

\footnotetext{
* Doutora em Letras - área de concentração Teorias do Texto e do Discurso. Professora do Programa de Pós-Graduaça o em Linguística Aplicada da Universidade Católica de Pelotas - UCPEL. Membro do Laboratório de Estudos em Análise de Discurso-LEAD/UCPELeGEPAD/UFRGS.eacazarin@gmail.com.br.

* Doutoranda do Programa de Pós-Graduação em Letras - UCPEL, Pelotas, RS. Mestre em Letras pela mesma universidade. Especialista em educaça pela Universidade Federal de Pelotas. Professora pesquisadora do Instituto Federal Sul-Rio-Grandense-IFSUL. mariacordeiro@ifsul.edu.br.
} 
ABSTRACT: This paper placed in Michel Pêcheux's discourse analysis has the purpose to analyze the statement "EU SOU SARTORI E MEU PARTIDO É O RIO GRANDE” pronounced by the candidate to the Rio Grande do Sul's government, José Ivo Sartori, during his campaign in 2014. With this investigation, we intend to offer reflections around issues that can, in the verticality of the discourse, help in the comprehension of the excess and the lack both present in the discursive operation in focus. These notions are conceived as limits and interdictions that are imposed on the subject, being the excess, the part that allows the effect of truth and the lack what works as forgetfulness policy. These operations establish meaning effects that can displace, transform, preserve and/or delete senses.

KEYWORDS: Politics discourse. Excess. Lack. Effect of truth. Forgetfulness policy.

\section{FORMULAÇÕES INTRODUTÓRIAS}

A Teoria da Análise de Discurso (AD) tem como seu maior interesse o discurso, a palavra em curso, o sujeito falando, buscando, assim, compreender o funcionamento da linguagem, os processos discursivos e o modo como o dizer produz um efeito de sentido e não outro. Considera a historicidade, o trabalho da história na língua, atenta para a importância do outro-outro ${ }^{1}$ na constituição do sujeito e do sentido, enfatizando que o sentido sempre pode ser outro, mas não qualquer um.

A AD concebe o dizível como portador de limites e de interdições, com as quais o sujeito enunciador se depara ao longo de suas práticas discursivas em decorrência da formação discursiva e da posição-sujeito na qual está inscrito. Tais restrições possibilitam apreender, pelo discurso, questões como a divisão e a dispersão do sujeito.

Assim, este texto tem como objeto de investigação um enunciado presente no discurso do então candidato ao governo do Estado do Rio Grande do Sul, José Ivo Sartori, durante a campanha eleitoral de 2014, veiculado repetidamente na propaganda eleitoral e na mídia. É de nosso interesse investigar de que modo um discurso voltado à persuasão se estabelece em função de características das subjetividades contemporâneas, produzindo prováveis deslocamentos, transformações, permanências e/ou apagamentos.

Para a análise que empreendemos, dedicamos especial atenção às condições de produção do enunciado, a elementos que foram silenciados e a sentidos que foram interditados, buscando compreender o excesso e a falta como consequência dos limites que são impostos ao sujeito.

\section{A PRÁTICA DISCURSIVA DO SUJEITO}

Diante do vasto material (superfície linguística) produzido durante o período eleitoral em pauta, elegemos para análise, neste artigo, apenas o enunciado "EU SOU SARTORI E O MEU PARTIDO É O RIO GRANDE". O referido enunciado fez parte da propaganda eleitoral e foi exibido durante todo o período da campanha do referido candidato. Daí o considerarmos como o slogan da campanha, o qual entendemos que é possível conceituar como o enunciado de base, termo cunhado por Denise Maldidier (1971 apud OSAKABE, 1999, p. 30-31) para referir-se à recorrência de determinado conteúdo, em que a autora considera as informações históricas sobre as condições em que foram pronunciados os discursos.

Não se trata de buscar certas recorrências previamente escolhidas entre enunciados, mas compreender esse enunciado como portador de uma invariante semântica que subjaz a todos os demais efeitos de sentido que se constroem em torno do sujeito, mostrado como o sujeito "ideal" para ocupar o cargo pleiteado. Isso nos faz pensar que há um sentido de base, ou seja, uma constante semântica. Em nosso entendimento, o enunciado objeto de nossa análise permite pensar as coerções a que o discurso de Sartori estava submetido, principalmente no que se refere às condições de sua produção, já que determinadas condições prévias

\footnotetext{
${ }^{1}$ A Análise de Discurso considera que o sujeito é determinado pelo ideológico e pelo inconsciente: "[...] o sujeito funciona no ordinário do dizer sob o efeito do apagamento da alteridade (exterioridade, historicidade), com a ilusão do sentido-lá, de sua evidência. A posição construída pelo analista visa não refletir essa ilusão, mas, ao contrário, trabalhá-la, levar em conta a questão da alteridade, tornando visível o modo como a ideologia opera" (ORLANDI, 2001, p. 26).
} 
delimitam o quadro de possibilidades do dizer, ou seja, o quadro de significações de um discurso depende do quadro situacional em que o mesmo se insere.

Na formulação de Osakabe (1999, p. 75), o discurso político pode ser compreendido em dois níveis, isto é, os discursos de tensão aquele conjunto de discursos que têm "[...] de certa forma, rarefeita sua função informativa e elevada ao extremo a sua função persuasiva" e, por outro lado, os discursos de prestação de contas, aqueles "nos quais a quase totalidade das páginas é dedicada à informação". No âmbito da AD, essa divisão em níveis não nos é produtiva, pois consideramos que mesmo um discurso informativo faz muito mais do que isso - a informação está mais para convencer, persuadir, do que para o ato informativo em si. Não obstante a isso, nos interessa a noção de discurso de tensão, que concebemos como sendo possível de tratar na perspectiva da $\mathrm{AD}$, pois a mesma conjuga uma instância ideológica, manifestações do inconsciente e certa intencionalidade do sujeito, características essas presentes no discurso em pauta.

Concebemos como uma das principais características deste enunciado o fato de deixar transparecer a movimentação de uma tentativa de desconstrução de sentidos em circulação ou, ainda, uma tentativa de recalcar determinados sentidos e antecipar outros $^{2}$ em decorrência da circulação de significações que produzem “[...] um mal estar simbólico na relação com o 'outro’ corompida, co-roída por práticas sociais que se historicizam por pesados processos de exclusão, de negação, de apagamento, de silenciamento" (ORLANDI, 2001, p. 209). Tal processo é que propomos denominar de efeito de desgaste imagético - desgaste político-partidário enfrentado pelo candidato do PMDB José Ivo Sartori e pelos demais sujeitos ligados à política partidária ${ }^{3}$ daquelas condições de produção. É justamente esse desgaste que o candidato pretende recalcar, pois, embora filiado a um partido político (o PMDB) e concorrendo como representante de uma frente político-partidária, evita, em toda a campanha, nomear o referido partido.

Entendemos que isso ocorreu tendo em vista o cenário político daquele momento histórico, o que aumentou o descrédito da política em geral, dos políticos e dos partidos políticos. A população estava perplexa diante de tantos escândalos, entre os maiores, o do "mensalão" e os desvios de recursos da Petrobrás, envolvendo principalmente políticos ligados ao governo do Partido dos Trabalhadores (PT) e ao PMDB, partidos que representavam, então, a situação. Neste ínterim havia um anseio pela responsabilização dos envolvidos. Não bastasse isso, temos, no Estado do RS, a história de insucessos de governos anteriores do PMDB. O sujeito do discurso, por sua vez, entendendo que tudo isso poderia refletir no voto do sujeito-eleitor, pautado no mecanismo de antecipação, optou pelo silenciamento do partido que representava - o PMDB.

Vale ressaltar que esse é um discurso de interesse fundamentalmente político, que, assim como os demais, faz mais do que informar, é um lugar a partir do qual o sujeito enunciador procura convencer, persuadir, impressionar e é, portanto, lugar de argumentação, apelo emotivo e observação de valores morais. O sujeito enunciador, em seu discurso, também sinaliza para uma suposta cultura da Paz, da Ternura, da Fraternidade, da Religiosidade, procurando contrapor-se a seus opositores.

Nesse sentido, nos interessa refazer esse caminho em que não só o dito, mas também o não dito ou o dito em outro lugar igualmente significam. Sabemos que o efeito de sentido tem história e essa história reverbera nos dizeres da contemporaneidade. Este enunciado, como todas as demais manifestações verbais e não verbais, é portador de uma rede intrincada de significações, inaugurando um espaço de movimentação do sujeito com potencial para mostrar seus prováveis deslocamentos, transformações e/ou apagamentos, e, portanto, o elegemos como representativo do excesso e da falta no discurso em questão.

\footnotetext{
${ }^{2} \mathrm{O}$ mecanismo da antecipação, mencionado por Pêcheux, prevê que o sujeito enunciador coloca-se no lugar de seu interlocutor e antecipa-lhe a resposta. Deste modo, o sujeito inconscientemente organiza seu discurso de determinada forma e não de outra, visando produzir efeitos de sentido que entende como possíveis produzir no interlocutor, o que configura uma das ilusões do sujeito. A antecipação reside na possibilidade que permite "[...] que o orador experimente de certa maneira o lugar do ouvinte a partir de seu próprio lugar de orador: sua habilidade de imaginar, de preceder o ouvinte é, às vezes, decisiva se ele sabe prever, em tempo hábil, onde o ouvinte o 'espera'. Esta antecipação do que o ouvinte vai pensar parece constitutiva de qualquer discurso[...]” (PÊCHEUX, 1997, p. 77, grifos do autor).

${ }^{3}$ A política partidária é aqui entendida como uma área especializada do saber, como espaço de conflito, litígio, desentendimento que ocorrem em uma cena em comum. A política é “[...] uma atividade que rompe a configuração sensível na qual se definem as parcelas e as partes ou a sua ausência a partir de um pressuposto que por definição não tem cabimento ali: a de uma parcela dos sem-parcela” - ocorre, assim, uma ruptura, uma reconfiguração do espaço no qual se definem as partes, as parcelas e suas ausências (RANCIÉRE, 1996, p.42-44). Já, o político, entendemos como "[...] representações do jogo de forças políticas em jogo no discurso, no qual interferem a história e a ideologia como constitutivas do discurso” (CAZARIN, 2004, p. 57).
} 
Diante do enunciado "EU SOU SARTORI E O MEU PARTIDO É O RIO GRANDE", nos deparamos com o emprego do pronome pessoal eu, primeira pessoa do singular, que Benveniste (1991, p. 225-36) trata como correlação de pessoalidade - conjunto eu/tu (a pessoa) em oposição a ele (a não-pessoa).

Segundo o mesmo autor, pronomes que se referem à pessoa (eu/tu) pertencem, pela própria relação de subjetividade que se estabelece entre eles, à instância do discurso, bem como a essa instância pertence tudo aquilo que a pessoa pode manipular em termos de sua subjetividade no interior do enunciado. Benveniste refere-se ao discurso como um espaço prático no qual a pessoa (eu/tu) ganha um estatuto de significado mais real do que virtual, como, também, à instância contemporânea do discurso, na qual existe uma realidade situacional provida de um locutor e de um ouvinte definidos no interior de determinado contexto.

Muito embora Benveniste nos ajude a entender a questão da subjetividade, deslocamos seu posicionamento para o âmbito da AD, teoria em que vamos tratar de sujeitos não empíricos e sim como representações que, a partir de formações imaginárias, designam o seu próprio lugar e o lugar do outro. Sercovich (1977, p.43-45) aborda o imaginário enquanto social, ou seja, concebe o imaginário discursivo como constituinte de uma das dimensões de toda prática social e complementa: "[...] lo imaginário discursivo y el efecto de transparência semiótica no se explican en absoluto por una relación - adecuada o no - con respecto a lo real sino por el hecho de derivar de determinados intereses sociales" (SERCOVICH, 1977, p. 44).

O autor cita Freud por este perceber com extraordinária clareza a relação do ilusório com o desejo e não por sua conexão com a realidade - "[...] una de las características más genuínas de la ilusión es la de tener su punto de partida en deseos humanos, de los cuales deriva” (SERCOVICH, 1977, p. 45). A contribuição de Sercovich consiste no fato de compreender que deslocando/substituindo a noção de desejos por interesses sociais se compreenderá como a ação do imaginário discursivo se integra à investigação das ideologias.

A partir do exposto podemos compreender que esse $e \mathfrak{u}$, no caso em pauta, vem carregado de um jogo de relações intersubjetivas que aí significam e produzem seus efeitos de sentido, pois essa subjetividade é concebida como constituída na relação com o social e o histórico. A esse eu agregam-se outros sentidos que, pelo viés da categoria da memória discursiva, podemos reconstituir, como é o caso de "o gringo que faz", enunciado também veiculado durante a campanha eleitoral. Em "o gringo que faz", é possível que tenha

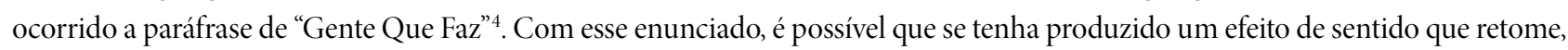
ainda que relativamente, o sentido produzido por uma campanha do extinto Banco Bamerindus.

A referida campanha cria um espaço de visibilidade para o banco, "Bamerindus, o Brasil se faz com gente que faz", a partir da apresentação de depoimentos motivadores de empreendedores, nos quais são contadas histórias de ambição, coragem, progresso e sucesso. Na campanha, é veiculada a ideia/imagem de gente que faz não somente para si, mas para seu semelhante, para sua comunidade, para seu país. Os protagonistas dessa série são, sem dúvida, apresentados como tendo um diferencial, como exemplos a serem seguidos.

Observamos, ainda, que além dos sentidos anteriormente mencionados agrega-se o adjetivo "gringo" e o determinante "o", que atribuem sentidos ao sujeito, a um imaginário que se pode pensar corrente a partir da história da imigração no Rio Grande do Sul 5 . Esse imaginário produz o efeito de sentido de que o estrangeiro, o imigrante italiano no caso em estudo, traz no sangue a história de coragem e de luta, que precisou primeiro desbravar terras improdutivas para depois obter o sucesso que é oriundo do seu trabalho. De certa forma, temos efeitos de sentidos que retomam outros, oriundos do interdiscurso, como o de que o povo brasileiro não gosta de trabalhar, sentidos ideologicamente performados que tentam justificar a desigualdade, a injustiça social e o abandono do

\footnotetext{
${ }^{4}$ A Biblioteca FEAUSP possui em seu acervo de vídeos a série “Gente que faz: histórias de ambição, coragem e progresso", produzida pela TV1 e apresentada por Sérgio Motta Mello, a série apresenta casos de sucesso, das décadas de 80 e 90, de empreendedores brasileiros. Disponível em: <https:/bibliotecafea.com/tag/genteque-faz/>. Acesso em: 29 nov. 2016. Também é possível obter mais informações em https://www.facebook.com/bancobamerindus/videod/591603310885714>. Acesso em: 29 nov. 2016

${ }^{5}$ Podemos contar com inúmeras obras e estudos que tomam por base a imigração italiana no Brasil, contudo encontramos em ZAGONEL e MANFROI (apud CONSTANTINO, 2011, p. 6-7), efeitos de sentido que enfatizam a história de coragem, heroísmo e superação de dificuldades dos colonos italianos, que permeia até hoje o imaginário colonial e a memória social.
} 
povo brasileiro por parte do Estado. O imaginário/imagem de "o gringo" se contrapõe ao sentido pejorativo atribuído à imagem do brasileiro e se firma sobre a ideia de determinação, coragem, trabalho e sucesso.

Desse modo, aos poucos esse eu vai sendo construído discursiva e imageticamente, produzindo um efeito de sustentação ao enunciado, procurando imprimir um caráter de veracidade e de um ideal promissor. Chamamos a atenção para este ponto, no qual nos deparamos com a possibilidade de trabalhar a materialidade linguística e sua exterioridade, o que pertence ao âmbito do interdiscurso e da memória discursiva que se faz presente e ali significa.

Cabe salientar que trabalhamos a noção de interdiscurso nos moldes que postula Indursky (2011). A natureza do interdiscurso é reunir todos os sentidos produzidos por vozes anônimas já esquecidas - tudo está lá. A memória discursiva diz respeito à formação discursiva, e, portanto, não comporta todos os sentidos, mas aqueles autorizados pela forma-sujeito no âmbito da FD em que o sujeito está inscrito. Indursky entende a memória discursiva como da ordem ideológica:

[...] é o ideológico que responde pela natureza lacunar de uma FD e da memória discursiva por ela representada [...]. O apagamento de um sentido em uma FD não implica o apagamento do sentido ao nível do interdiscurso, que funciona como uma memória de todos os dizeres. [...] entendemos que tanto memória discursiva como interdiscurso dizem respeito à memória social, mas não se confundem. Há diferenças importantes entre as duas noções. A memória discursiva é regionalizada, circunscrita ao que pode ser dito em uma FD e, por essa razão, é esburacada, lacunar. Já o interdiscurso abarca a memória discursiva referente ao complexo de todas as FD. Ou seja, a memória que o interdiscurso compreende é uma memória ampla, totalizante e, por conseguinte, saturada. (INDURSKY, 2011, p. 87-88, grifo da autora).

Ao mobilizar tanto a memória quanto o interdiscurso, diferentes funcionamentos podem ser acionados, reverberando, portanto, em outras palavras, sentidos iguais ou diferentes. Por outro lado, lembramos que é entre o mesmo e o diferente, entre o já-dito e o a se dizer, que sujeitos e sentidos se movimentam, se significam e o fazem porque o real da língua está sujeito à falha, o real da história é passível de ruptura, conforme argumenta Orlandi (2012, p.36-37):

[...] se o real da língua não fosse sujeito à falha e o real da história não fosse passível de ruptura não haveria transformação, não haveria movimento possível, nem dos sujeitos nem dos sentidos. É porque a língua é sujeita ao equívoco e a ideologia é um ritual com falhas que o sujeito, ao significar, se significa. Por isso, dizemos que a incompletude é a condição da linguagem: nem os sujeitos nem os sentidos, logo, nem o discurso, já estão prontos e acabados. Eles estão sempre se fazendo, havendo um trabalho contínuo, um movimento constante do simbólico e da história. É condição de existência dos sujeitos e dos sentidos: constituírem-se na relação tensa entre paráfrase e polissemia.

Retomando essa referência em relação à movimentação do sentido, recorremos a Pêcheux (1995, p.168), segundo o qual, “[...] o deslocamento do presente ao passado, acoplado ao deslocamento de um sujeito a outros sujeitos, constitui a identificação”. A partir dessa identificação, imbuído do sentimento de pertencimento a um domínio de saber, é que o sujeito, tomando posição, enuncia. Portanto, é nesse movimento entre passado/presente, entre intradiscurso/interdiscurso, entre o mesmo e o diferente que o sentido se constitui.

Desse modo, interessa-nos para este estudo a forma como os sentidos se constituem, ou seja, pela repetição, viabilizados pelo "novo", pelo possível, pelo diferente. Nossas análises estão pautadas nas noções de excesso e de falta (ERNST, 2009), conforme já mencionado, buscando compreender seus possíveis entrelaçamentos com noções como o silenciamento e/ou a denegação do discurso-outro. 


\section{O EXCESSO NO DISCURSO}

$\mathrm{Na}$ análise, constatamos que o excesso fica por conta do uso exaustivo do enunciado "EU SOU SARTORI E O MEU PARTIDO É O RIO GRANDE”, valorizando o paradigma pessoal para a elaboração de representações de si, ensejando estabelecer uma relação de solidariedade e de identificação entre o locutor-sujeito-candidato e o interlocutor-sujeito-eleitor.

O excesso, entendido a partir de Ernst (2009, p. 4) como “[...] estratégia discursiva que se caracteriza por aquilo que está demasiadamente presente no discurso", pode ocorrer de duas maneiras:

1) no uso de incisas, considerado na gramática como um acréscimo contingente (cf. Haroche, 1992), de intensificadores ou na repetição de palavras ou expressões e orações. Tais usos, na perspectiva aqui adotada, constituem-se em 'acréscimo necessário’ ao sujeito que visa garantir a estabilização de determinados efeitos de sentido em vista da iminência (e perigo) de outros a esses se sobreporem;

2) na reiteração incessante de determinados saberes interdiscursivos que tomam formas diferentes no intradiscurso, mas mantêm os mesmos pressupostos ideológicos com vistas ao estabelecimento. Em suma, trata-se, nos dois casos, de buscar estabelecer provavelmente a relevância de saberes de uma determinada formação discursiva através da repetição (ERNST, 2009, p. 4).

3)

No caso em análise, o desejo de eleição funciona como a causa que leva à materialização do excesso pelo viés de repetição. SerraniInfante (1991, p. 93-100) considera que uma das principais condições de possibilidade da Análise de Discurso é a repetição e identifica como um dos modos exemplares de repetição a paráfrase ${ }^{6}$.

Da concepção anteriormente mencionada, resta-nos, pois, compreender que não há repetição pura, já que as condições de produção e reprodução de um determinado enunciado não são as mesmas. Ainda que o enunciado tenha sido repetido inúmeras vezes durante a campanha eleitoral, há um jogo interdiscursivo (o atravessamento por outros discursos, já ditos, já significados anteriormente, diferentes condições de produção-reprodução) que sobre ele atua. Para a análise que estamos a realizar, interessanos substancialmente o estudo da repetição e a contribuição que a mesma possa trazer para a compreensão dos sentidos que se constituem e circulam em torno do sujeito do discurso.

A questão do excesso pode ser articulada ou, melhor, entrelaça-se às questões da memória, da repetição. Assim, de acordo com Pêcheux, a memória em AD:

[...] deve ser entendida não no sentido psicologista da "memória individual", mas nos sentidos entrecruzados da memória mítica, social, inscrita em práticas [...]. A memória discursiva seria aquilo que, em face de um texto que surge como acontecimento a ler, vem restabelecer os 'implícitos' (quer dizer, mais tecnicamente, os préconstruídos, elementos citados e relatados, discursos transversos, etc.) de que sua leitura necessita: a condição do legível em relação ao próprio legível (PÊCHEUX, 1999, p. 51-52, grifo do autor).

Na mesma direção, Indursky (2011, p. 68) pontua que “[...] a reflexão sobre memória sempre esteve presente no quadro da Teoria da Análise de Discurso", ainda que sob outras designações, como, por exemplo, repetição, pré-construído, discurso transverso, interdiscurso. Vale dizer que “[...]não há dizer que para fazer sentido não se inscreva na memória. Não há dizer que não se faça a partir da repetição" (ORLANDI, 2012a, p.173).

No entanto, sabemos que a repetição que interessa à $\mathrm{AD}$ e, consequentemente, à nossa análise, é a repetição histórica, ou seja, aquela em que "há deslocamento, deriva, transferência, efeito metafórico. E o efeito metafórico é retomada e esquecimento, deslize para outro lugar de sentido, novo gesto de interpretação" (ORLANDI, 2012a, p. 173).

O que podemos perceber é que há um continuum de efeito de sentido, o sujeito se esforça para manter o mesmo discurso,

\footnotetext{
${ }^{6} \mathrm{~A}$ paráfrase apresenta-se como uma possibilidade de compreensão do funcionamento discursivo do que pré-existe ao discurso, mas que sobre este produz seus efeitos. Em AD a paráfrase é entendida como uma possibilidade de diversificação do sentido. Segundo Orlandi (2012, p.79), vemos a historicidade representada pelos deslizes produzidos nas relações de paráfrase, lembrando que em $\mathrm{AD}$ não existe paráfrase pura.
} 
reforçando, assim, o aprendizado, ou seja, a regularização de um determinado sentido, o que nos remete para o fato que "há repetições que fazem discurso" (COURTINE; MARANDIN, 1981 apud INDURSKY, 2011, p. 28).

Esse e outros pontos nos levam a compreender a repetição como uma possibilidade de condensação das semelhanças de sentidos, sem deixar de mostrar que os mesmos estão sempre vinculados à possibilidade de movimentação e que, por isso, o sentido sempre pode ser outro e a repetição pode ocorrer de maneira relativa. No entanto, não podemos deixar de reconhecer que a repetição através dos tempos instaura a regularização e funciona a partir de suas imagens enunciativas criadas a partir da memória e que também produz memória.

É interessante observar que esse processo de construção do sentido se constitui essencialmente através do Aparelho Ideológico de Estado da Informação, o qual, de acordo com Indursky (2015, p. 14), é responsável pela instauração de Políticas do Esquecimento, produzindo um processo discursivo que é da ordem da repetibilidade.

Ao considerar as condições de produção desse discurso, nos deparamos com o fato de que o mesmo ocorre fortemente ligado a saberes específicos que são repetidos exaustivamente procurando produzir um efeito de verdade. E, neste processo, uma posição passa a ser tomada como única, verdadeira, enquanto outras passam a ser excluídas produzindo, assim, conforme a autora recém citada, "gestos de silenciamento em torno de outros possíveis sentidos". Trata-se de um silêncio específico-particular, que se produz porque

[...] as práticas e os saberes excluídos remetem a um outro modo de se relacionar com a ideologia e divergem e/ou antagonizam com os saberes e interesses da Formação Discursiva Dominante. Essas outras vozes são excluídas do âmbito da Formação Discursiva [...]. Tal procedimento produz um efeito de silenciamento do diferente, responsável pelo efeito de consenso instaurado no corpo social (INDURSKY, 2015, p. 15, grifo da autora).

Acreditamos que aqui se abre um espaço para pensar o sujeito do discurso como portador de certa intencionalidade (ainda que nada lhe garanta a efetivação da mesma), com objetivos e metas que não combinam com a AD, mas que fazem parte das condições de produção de candidato. Sob a ilusão de ser a origem do que diz e de que seu dizer não poderia ser dito de outra forma, candidato e equipe trabalham a argumentação pelo viés da repetição de argumentos que antecipadamente julgam que devam ser reiterados.

O excesso, no discurso em pauta, também pode estar estreitamente relacionado às formas de representação do sujeito no discurso político, lugar de construção de representações próprias, com vistas a atender um objetivo específico, e, no caso, vencer a eleição. Em seu processo discursivo, pelo regime da repetibilidade, o sujeito privilegia uma posição, silencia diferenças e/ou divergências, recalca o que não entende como interessante ou favorável para ficar lá onde Indursky denomina de dobradura da memória ${ }^{7}$. Isso até que, por um gesto de resgate da memória, no movimento entre excesso e falta essa dobradura possa novamente se abrir e permitir que o sentido venha a se alternar, a ser outro.

\section{A FALTA NO DISCURSO}

Passemos, agora, ao discurso da falta. Esta, segundo Ernst, "[...] pode ocorrer, no nível intradiscursivo, através de diferentes processos de ordem sintática e lexical" (2009, p. 4), as quais, no âmbito da AD, possuem outro estatuto, ou seja, deixam de ser interpretadas como formas de dizer vinculadas às intenções estéticas de quem as usa, para serem consideradas em relação às determinações históricas de quem as produz.

Outra autora que nos ajuda a entender a falta é Morales que, em seu artigo Sujeito; Imaginário; Simbólico e Real: deslizamentos de sentido (2008, p. 34-46), nos apresenta a falta como pré-existente ao sujeito. Em sua discussão, a autora situa a fase do espelho como

${ }^{7}$ Indursky (2015, p. 16-17) refere-se que pelo regime de repetição o sujeito do discurso busca calcar à força na memória social determinados sentidos e, ao mesmo tempo, este mesmo procedimento silencia posições diferentes e/ou divergentes, recalcando-as em uma zona do interdiscurso, que denomina de dobradura da memória. 
[...] o momento em que o sujeito se defronta com sua imagem. Reconhecer no espelho sua própria imagem é decisivo na constituição do sujeito. Esta identificação primeira do indivíduo com sua imagem é a origem das demais identificações. É uma identificação imediata e "dual", reduzida a dois termos, o corpo e sua imagem. Lacan a qualifica de imaginária, porque o indivíduo se identifica com uma cópia de si mesmo, com uma imagem que não é ele mesmo, mas que lhe permite reconhecer-se. Ao fazê-lo, preenche um vazio entre os dois termos da relação: o corpo e a imagem. Trata-se de uma relação caracterizada pela indistinção, a confusão entre si mesmo e o outro, e também pela alienação, porque o sujeito não tem nenhuma distância frente a sua própria imagem, confundindo seu corpo com o do semelhante (MORALES, 2008, p. 37).

Podemos entender que nessa passagem de indivíduo a sujeito - momento em que o sujeito se identifica com sua própria imagem - está presente a falta, ou seja, há aí um espaço vazio, pois o sujeito é mais do que a imagem que vê diante do espelho. Portanto, essa falta, esse espaço vazio, é preenchido imaginariamente e a fase do espelho constitui/contribui tanto para a obtenção de uma unidade subjetiva, permitindo uma primeira localização do corpo, quanto determina a alienação, submissão do futuro sujeito a sua própria imagem.

Pelo exposto, na aproximação da Análise de Discurso com a psicanálise entendemos o sujeito como constituído por uma falta que, ao mesmo tempo em que o habita, o torna um sujeito desejante. Parafraseando Morales (2008), o sujeito que está submetido à linguagem e a sua incompletude é sujeito em falta, desejante. Considerando que a falta se presentifica no sujeito, na linguagem e no sentido, continuamos nossa reflexão retornando a Ernst, quando esta, numa perspectiva discursiva, apresenta a falta, como:

Estratégia discursiva que consiste em: 1) na omissão de palavras, expressões e ou orações, consentida inclusive pela gramática, que podem (ou não) ser resgatada pelo sujeito-interlocutor; 2) na omissão de elementos interdiscursivos que são esperados, mas não ocorrem e podem (ou não) ser percebidos pelo sujeitointerlocutor. No primeiro caso ela se constitui num lugar em que são criadas zonas de obscuridade e incompletude na cadeia significante com fins ideológicos determinados; no segundo, cria um vazio que visa, na maioria das vezes, encobrir pressupostos ideológicos ameaçadores (ERNST, 2009, p. 4).

Diante do exposto, retomamos o enunciado EU SOU SARTORI E O MEU PARTIDO É O RIO GRANDE para analisarmos a falta. Preliminarmente, essa falta, essa presença/ausência que se instala no enunciado do sujeito enunciador, não é de ordem sintática não há falta na estrutura do enunciado. No entanto, se presentifica a possibilidade de diferentes interpretações, o que ratifica a ideia de que o sentido sempre pode ser outro, pois é preciso considerar que há um espaço inatingível entre o que é dito e o que é interpretado.

A falta aqui funciona pela omissão, isto é, ao invés de dizer o PMDB é o meu partido, há um silenciamento do partido, de sua história, da memória e também de efeitos de sentido que circulavam à época, no momento em que o sujeito enunciador dizia meu partido é o Rio Grande. Com isso, o sujeito possibilita, no mínimo, a produção de efeitos de sentido distintos, um que afirma que o Rio Grande é maior, mais importante, e que, portanto, estaria acima de partidos políticos, de ideologias e interesses particulares, e outro que enaltece o próprio sujeito, colocando-o como alguém que não se deixa levar por interesses partidários, ideológicos ou interesses próprios, que estaria acima de quaisquer partidos ou até mesmo o desejo de recalcar o nome do partido que lhe empresta a sigla.

É possível conceber que essa falta ocorre sob a figura da denegação, ou seja, a cena discursiva comporta a possibilidade para que o partido (PMDB), o qual o sujeito enunciador representa, seja referido. No entanto, ocorre justamente o contrário e tal posicionamento não é comum na conjuntura dada (não é comum a apresentação de um candidato que não mencione ou que deseje se desvincular do partido pelo qual concorre ao cargo pretendido). É a esse sentido que nos referimos acima, pois, ao afirmar "meu partido é o Rio Grande" o sujeito "nega/recalca” o partido a que pertence e isso nos fornece outra pista: "[...] através da denegação, o sujeito diz sem, de fato, dizer, apresentando-se dividido entre seu desejo de dizer e sua necessidade de recalcar" (INDURSKY, 1990, p.118).

Para elucidar essa questão, retomamos a autora recém citada, quando afirma que o sujeito pode se relacionar com saberes de outras 
formações discursivas, saberes antagônicos, os quais estão interditados em seu discurso, mas isso não é o que acontece no discurso que estamos analisando. Não se trata de um saber exterior, mas de um saber interior próprio da FD do sujeito que passa a ser implicitamente silenciado.

Em seu estudo, a autora desloca o conceito de denegação da psicanálise para a AD, propondo, então, que se considere a denegação discursiva:

[...] como aquela negação que incide sobre um elemento do saber próprio à FD que afeta o sujeito do discurso. Ou seja, a denegação discursiva relaciona-se com a interioridade da FD e com o modo como o sujeito com ela se relaciona. Assim, seu efeito não é polêmico. Ao incidir sobre um elemento de saber que pode ser dito pelo sujeito do discurso mas que, mesmo assim, por ele é negado, tal elemento permanece recalcado na FD, manifestando-se em seu discurso apenas através da modalidade negativa (INDURSKY, 1990, p. 120, grifos da autora).

Diante do exposto, embora não haja uma negativa explícita de saberes próprios à FD por parte do sujeito, entendemos que a denegação discursiva é uma noção que pode ser aplicada à análise que estamos empreendendo, pois o recalque/o silêncio pode estar funcionando como negação de um saber e/ou prática que esteja circulando no interior da FD em que se inscreve o sujeito.

Podemos observar que ocorre a falta de um elemento que costuma usualmente aparecer em situação semelhante, mas que foi silenciado. Esse silenciamento é possível de ser interpretado como um deslocamento no discurso (PÊCHEUX, 1997, p.77). Ou seja, o sujeito enunciador, a partir da imagem e do lugar que atribui ao outro, seu interlocutor, pretensamente antevê o que o outro gostaria ou não gostaria de ouvir. Dito diferentemente: o sujeito, imaginariamente, passa de seu lugar ao lugar do outro e isso lhe permite, ainda que num processo ilusório, antecipar o lugar em que o ouvinte lhe espera. Assim, lança mão de procedimentos linguísticos e discursivos para organizar seu discurso, tendo por finalidade produzir determinado efeito de sentido, ainda que inconscientemente.

No nosso ponto de vista, essa falta pode ser compreendida como um desejo consciente-inconsciente de conquistar a simpatiaidentificação do sujeito-eleitor. Concebemos essa falta como uma antecipação, como o desejo de silenciar o que entende que não lhe seja favorável. O sujeito do discurso enuncia, se representa/é apresentado como um simulacro ${ }^{8}$ da imagem de candidato ideal que se preocupa com o futuro do Estado, construindo-se a partir da imagem que é entendida como aquela desejada pelos eleitores. Assim, a imagem de candidato ideal é construída sobre a suposta imagem que os eleitores possuem e/ou desejam.

Isso reforça que o sujeito enuncia com base no lugar institucional no qual está investido (lugar de candidato ao governo do Estado), apresentando-se, desta forma, fortemente atravessado pelo imaginário, que serve de base para a construção de uma imagem que corresponda ao modo como entende que deva ser visto pelo outro.

Ainda guiadas pelo desejo-necessidade de melhor compreender a falta, passamos a analisá-la à luz do que Indursky (2015, p. 11-27) nomeia de políticas do esquecimento. Nesse trabalho, a autora apresenta as políticas do esquecimento como forma de subjetivação antagônica em relação às políticas de resgate de memória, ambas concebidas como modalidades de funcionamento da memória social ${ }^{9}$. Vale ressaltar que ambas são reconhecidas como representativas de um jogo de forças, "[...] uma luta de poder entre a memória e o esquecimento" (INDURSKY, 2015, p. 14). Podemos entender a partir do que explicita a autora, as políticas do esquecimento como aquelas práticas que possibilitam a "[...] produção de um véu de esquecimento sobre o passado recente" (INDURSKY, 2015, p. 14), em outras palavras, uma tentativa de encobrimento desse passado-recente-presente.

\footnotetext{
${ }^{8}$ Noção cunhada por Deleuze (1974, p. 263) e explicitada pelo autor como diferente da cópia: "a cópia é uma imagem de semelhança, o simulacro, uma imagem sem semelhança [...]. O simulacro produz um efeito de semelhança”.

${ }^{9}$ Entendida pela autora "[...] como um conjunto de saberes regulados por Aparelhos Ideológicos de Estado, filtrados e discursivizados por práticas inscritas em Formações Discursivas. Tais saberes apontam para o que o corpo social imaginariamente retém tanto de passado remoto quanto de um passado mais recente. No entanto, o sujeito do discurso, em suas práticas discursivas, não a domina plenamente e a mobiliza pelo viés de uma memória fluída, que é atravessada pelo inconsciente e marcada pela vagueza e mesmo pelo equívoco e pelo desconhecimento" (INDURSKY, 2015, p. 12).
} 
Acreditamos, portanto, que, no caso em análise, seja possível compreender a falta como algo que poderia ser afirmado, mas não o é, fazendo com que o discurso do sujeito, como já referido, produza um efeito de sentido muito próximo da denegação ou mesmo daquilo que a autora vem tratando como políticas do esquecimento (INDURSKY, 2015).

\section{EFEITO DE FECHAMENTO}

Partindo do que nos apresenta Ernst, concluímos que o excesso fica por conta da repetição que se dá pelo sentimento de um acréscimo necessário em virtude do perigo e iminência de outros efeitos de sentido (os não desejados) virem à tona, como também ocorre em vista do estabelecimento de pressupostos ideológicos desejáveis.

Assim, pelo viés da repetibilidade, o mesmo é reiterado inúmeras vezes, não para colocar uma posição como a única, pois existem outras posições, outros sujeitos-candidatos, mas para que uma posição se sobreponha às demais, produzindo um efeito de verdade, ou seja, a posição personifica a verdade.

No que diz respeito à falta compreendida em nosso estudo, ocorre pela conjugação de dois elementos, ou seja, a "[...] ocultação de elementos do interdiscurso de uma dada formação discursiva” (ERNST, 2009, p.4) e as determinações históricas de quem as produz. Acrescente-se a isso que o sujeito vem dizer de outro modo, ou seja, organiza seu dizer movido pela ilusão de desfazer o caos a que está submetido por força de efeitos de sentido que circulam em relação ao partido que representa.

Para Orlandi (2012a, p. 231), a falha abre espaço para a possibilidade de o sujeito irromper com seus outros sentidos, é "[...] condição para que os sujeitos e os sentidos possam ser outros, 'fazendo sentido do interior do não-sentido"'. Compreendemos que esse "não-sentido" que permite a produção do sentido pode ser também a falta, ou seja, o ausente que não se presentifica, mas que ali significa.

A falta da qual estamos tratando não se refere ao que está sendo dito de menos, mas ao que está deixando de ser dito, o que é esperado e deixa de ser nomeado, isto é, o partido ao qual pertence o sujeito-candidato ao Governo do Estado do Rio Grande do Sul. E esse não dito não o é por acaso, constitui-se na criação de zonas de obscuridade e o vazio que aí se cria ou é criado com algum propósito - visa encobrir o que é ameaçador, o que não é favorável (ERNST, 2009, p. 4).

A partir do percurso que fizemos, compreendemos "os procedimentos que buscam calcar à força na memória social determinados sentidos que remetem a uma determinada posição-sujeito", seja pela repetibilidade-excesso, seja pela falta-silenciamento, silenciam efeitos de sentidos e posições-sujeito diferentes, "recalcando-os em uma zona do interdiscurso", e, portanto, o funcionamento discursivo do excesso e da falta aproxima-se, entrelaça-se com o que Indursky (2015, p. 17) denomina de dobradura da memória. Ou seja, os dois processos, ainda que antagônicos, remetem a um efeito de suspensão do sentido.

Deste modo, tanto o que é demasiadamente repetido como o que deixa de ser dito funcionam como um esforço do sujeito para manter lá, bem num cantinho da dobradura da memória, aquilo que ele entende como ameaçador, como o que não convém ser dito. E o papel de analista de discurso nos coloca na posição de resgatar esses efeitos de sentido que vão sendo deixados-esquecidos pelo meio do caminho. É ultrapassando os limites do linguístico que nos permitimos reconstituir a historicidade do enunciado do candidato José Ivo Sartori, já que a mesma pode (ou não) ter sido compreendida pelo sujeito-interlocutor-eleitor.

Ao finalizar, sabemos que muito ainda pode ser dito e que entre o excesso e a falta o sujeito produz sentidos e se constitui numa prática que é tanto discursiva quanto social. 


\section{REFERÊNCIAS}

BENVENISTE, Émile. Problemas de lingüística geral I. Tradução Maria da Glória Novak e Maria Luiza Neri. 3. ed. Campinas, SP: Pontes: Editora da Universidade Estadual de Campinas, 1991.

CAZARIN, E. A. Identificação e representação política: uma análise de discurso de Lula (1978 - 1998). 2004. 270f. Tese (Doutorado em Letras) - Programa de Pós-Graduação em Letras, Universidade Federal do Rio Grande do Sul, Porto Alegre, 2004.

CONSTANTINO, Núcia Santoro de. Estudos de imigração italiana: tendências historiográficas no Brasil meridional. In: SIMPÓSIO NACIONAL DE HISTÓRIA, 26, 2011, São Paulo. Anais... São Paulo: ANPUH, jul. 2011. Disponível em: <http://www.snh2011.anpuh.org/arquivo/download?ID_ARQUIVO=24379>. Acesso em: 05 dez. 2016.

DELEUZE, Gilles. Lógica do sentido. Tradução de Luiz Roberto Salinas Fortes. São Paulo: Perspectiva, Ed. da Universidade de São Paulo, 1974.

ERNST, A. G. A falta, o excesso e o estranhamento na constituição/interpretação do corpus discursivo. In: SEMINÁRIO DE ESTUdOS EM ANÁLISE DO DISCURSO, 4., 2009, Porto Alegre, RS. Anais... Porto Alegre: UFRGS, 2009. Disponível em: $<$ http://anaisdosead.com.br/4SEAD/SIMPOSIOS/AracyErnstPereira.pdf>. Acesso em: 17 maio 2016.

INDURSKY, Freda. Polêmica e Denegação: dois funcionamentos discursivos da negação. Cadernos de Estudos Linguísticos, Campinas, SP, n. 19, p. 117-122, 1990.

. A memória na cena do discurso. In: INDURSKY, Freda; MITTMANN, Solange; FERREIRA, Maria Cristina Leandro (Org.). Memória e história na/da análise de discurso. Campinas, SP: Mercado de Letras, 2011. p. 67-89.

Políticas do Esquecimento X Políticas de Resgate da Memória. In: FLORES, Giovana G. B; NECKEL, Nádia R. M; GALLO, Solange Maria Leda (Org.). Análise de discurso em rede: cultura e mídia. v. 1. Campinas, SP: Pontes, 2015. p.11-27.

MORALES, Vieira de Souza Blanca. Sujeito; Imaginário; simbólico e real: deslizamento de sentidos. In: MITTMANN, S.; GRIGOleTTO, E.; CAZARIN, E (Org.). Práticas discursivas e identitárias: sujeito e língua. Porto Alegre: Nova Prova, 2008. p. $34-46$.

ORLANDI, Eni Puccinelli. Discurso e texto: formulação e circulação dos sentidos. Pontes, Campinas, SP, 2001.

. Análise de discurso: princípios e procedimentos. Campinas: Pontes, 2012.

. Discurso em análise: sujeito, sentido, ideologia. Campinas: Pontes, 2012a.

OSAKABE, Haquira. Argumentação e discurso político. 2. ed. São Paulo: Martins Fontes, 1999.

PÊCHEUX, Michel. Semântica e discurso: uma crítica à afirmação do óbvio. Trad. Eni Puccinelli Orlandi. 3. ed. Campinas: Editora da Unicamp, 1995.

Análise automática do discurso (AAD-69). In: GADET, Françoise; HAK, Tony. Por uma análise automática do discurso. 3. ed. Campinas: Unicamp, 1997.p. 59-158.

. Papel da memória. In: ACHARD, Pierre et al. Papel da memória. Campinas: Pontes, 1999. p. 49-56. 
RANCIÈRE, Jacques. O desentendimento: política e filosofia. São Paulo: Editora 34, 1996.

SERCOVICH, A. El discurso, el psiquismo y el registro imaginario. Buenos Aires: Nueva Vision, 1977.

SERRANI-INFANTE, Silvana. A paráfrase como ressonância interdiscursiva na construção do imaginário de língua: o caso do Espanhol Riopratense. 1991. 327f. Tese (Doutorado em Ciências da Linguagem) - Universidade Estadual de Campinas, Campinas, 1991. 